\title{
Depressive symptoms among metabolically healthy and unhealthy overweight/obese individuals: a comparative study
}

\author{
Somaye Yosaee ${ }^{1,2}$, Kurosh Djafarian ${ }^{3}$, Alireza Esteghamati ${ }^{4}$, Abbas Motevalian ${ }^{1}$, Farzad Shidfar ${ }^{5,1}$, \\ Mehdi Tehrani-Doost ${ }^{6}$, Shima Jazayeri*5,1
}

Received: 30 Feb 2018

Published: 1 Oct 2018

\section{Abstract}

Background: Although a growing body of evidence suggests an association between obesity and depressive disorder, the association remains inconclusive. Metabolically healthy obese (MHO) phenotype, defined by favorable lipid profile, and normal insulin sensitivity, blood pressure, may be considered as a possible explanation for these inconsistencies. Accordingly, this study aimed to compare depression score among metabolic unhealthy obese (MUO) and age- and sex-matched healthy controls.

Methods: In this comparative study including 157 Iranian adults, we assigned participants into three groups (non-obese metabolic healthy group, MHO and MUO) according to the BMI cutoff and MetS criteria. Depressive symptoms were assessed by Beck Depression Inventory. Analysis was done using SPSS version 14.0. All variables are expressed as means \pm SD. One-way ANOVA and multiple linear regression were used for data analysis.

Results: After adjustment for sex, marital status and educational level, MUO participants had significantly higher Beck depression score $(p=0.036)$ compared to MHO and non-obese metabolic healthy groups. After adjustment for demographic variables, there was a significant association between waist circumference $(\beta=0.142, \mathrm{p}=0.023)$, BMI $(\beta=0.347, \mathrm{p}=0.037)$, FBS $(\beta=0.096, \mathrm{p}<0.001)$, and the number of MetS components $(\beta=1.71, p=0.002)$ with depression score.

Conclusion: $\mathrm{MHO}$ was a benign phenotype in relation to depression.

Keywords: Depressive symptom, MetS, Obesity

\author{
Conflicts of Interest: None declared \\ Funding: None declared \\ *This work has been published under CC BY-NC-SA 1.0 license. \\ Copyright $\subseteq$ Iran University of Medical Sciences
}

Cite this article as: Yosaee S, Djafarian K, Esteghamati A, Motevalian A, Shidfar F, Tehrani-Doost M, Jazayeri Sh. Metabolic healthy and unhealthy obese phenotypes and depressive symptoms: A comparative study of metabolic healthy and unhealthy obese phenotypes and non-obese group. Med $J$ Islam Repub Iran. 2018 (1 Oct);32:95. https://doi.org/10.14196/mjiri.32.95

\section{Introduction}

Mood disorders, particularly depression, represent a major concern in obese subjects (1-3). Although available evidence suggests that obesity is likely to have important impacts on the occurrence of major depression $(1,2)$, the results of these studies were inconsistent $(2,4)$, and not all obese persons have depressive symptoms (4). A subset of obese individuals who are free of unfavorable metabolic

Corresponding author: Dr Shima Jazayeri, sh_jaz@yahoo.com

1. School of Public Health, Iran University of Medical Sciences, Tehran, Iran 2. School of Health, Larestan University of Medical Sciences, Larestan, Iran 3. School of Nutrition Sciences, Tehran University of Medical Sciences, Tehran, Iran.

4. Endocrinology and Metabolism Research Center (EMRC), Vali-Asr Hospital, Tehran University of Medical Sciences, Tehran, Iran

5. Research Center for Prevention of Cardiovascular Disease, Institute of Endocrinology \& Metabolism, Iran University of Medical Sciences, Tehran, Iran

6. Department of Psychiatry School of Medicine, Roozbeh Psychiatry Hospital Tehran University of Medical Sciences, Tehran, Iran profiles so-called "metabolically healthy obesity" (MHO) may be considered as a possible explanation for these inconsistencies $(5,6)$. MHO subject is characterized by normal insulin sensitivity, blood pressure, and favorable lipid and inflammatory profiles, despite excess body fat $(7,8)$.

To our knowledge, only few studies examined the

$\uparrow$ What is "already known" in this topic:

Depression, represent a major concern in obese subjects, however not all obese persons have depressive symptoms. Metabolically healthy obese (MHO) phenotype, subjects with favorable lipid profile, and normal insulin sensitivity, blood pressure, may be considered as a possible explanation for these inconsistencies.

$\rightarrow$ What this article adds:

In obese subjects, metabolic profile status rather than obesity is associated with risk of depression. 
relation between mood disorder and MHO phenotype (6, 9-11). A pooled analysis study reported that MHO and MUO subjects had a mildly increased risk of depressionrelated symptoms compared to all non-obese subjects (10). Furthermore, data from Hamer et al. suggested an elevated risk for depressive symptoms among MUO, but not among MHO individuals, after a 2-year follow-up (6). However further work is required to confirm these findings.

The present study aimed to compare the depression status, between metabolic unhealthy obese (MUO) subjects with age and sex-matched healthy controls.

\section{Methods}

\section{Study design and subject recruitment}

One hundred fifty-seven adult subjects (20-55 years) participated in this cross-sectional study. The participants were divided into three groups: metabolically unhealthy overweight/obese (MUO), metabolically healthy overweight/obese (MHO) and non-obese metabolically healthy participants. The MUO, MetS patients were recruited from patients referred to the Endocrinology Center of Tehran University of Medical Sciences. The metabolically healthy groups (MHO and non-obese metabolically healthy) were age- and gender-matched to the MUO, made up of 64 weight-matched overweight/obese subjects without MetS, the "metabolically healthy obese" (MHO) and 40 non-obese metabolically healthy. MetS was diagnosed according to the National Cholesterol Education program - Adult Treatment Panel III (NCEP-ATP III) criteria (12) .

Inclusion criteria were having a $\mathrm{BMI} \geq 25$ for the overweight/obese subjects and a BMI of 20-25 for the normal weight participants, age range 20-55 years and provided written consent of participation. Having any history of neurological (e.g., concussion, stroke, tumor, neuroinflammatory diseases) and medical conditions (e.g., cancer, chronic inflammatory or autoimmune diseases, heart diseases, diabetes mellitus, infections) as well as regular intake of medication and considered as exclusion criteria. Other non-pathological exclusion criteria included pregnancy, breastfeeding, post-menopause, smoking, professional athlete, having a special diet for any reason prescribed by the clinic dietitian, taking nutritional supplements and uncontrolled thyroid disorder. The study was approved by the ethics committee of Iran University of Medical Sciences (Ethic Number: 93-02-27-24976).

\section{Assessment and measurement}

Participants' body weight was measured in light clothing and without shoes (in kilograms $-\mathrm{kg}$ ) using calibrate scale (Model 700, USA). Standing height was measured to nearest $1 \mathrm{~mm}$ using a Seca stadiometer (Model 700, USA) while subjects were barefoot, and their shoulders were in a normal position. Body Mass Index (BMI) of each participant was calculated as body weight divided by height squared $(\mathrm{kg} / \mathrm{m} 2)$ to the nearest $0.01 \mathrm{~kg}$ and $0.1 \mathrm{~cm}$. Waist circumference (13) was measured between the lower rib margin and the iliac crest using a flexible tape measure after normal expiration. Blood pressure was measured twice separately over a 5-min interval by a professional nurse. The average of 2 measurements was considered as blood pressure value. Levels of TG, HDL-c, and FBS were evaluated from yearly patients' medical chart records. The Beck Depression Inventory (BDI) (14) was used to assess depressive symptoms.

\section{Statistical analysis}

Analysis was done using SPSS version 14.0 for Windows (Chicago, Illinois, USA). All variables are expressed as means $\pm \mathrm{SD}$. Comparisons between the three groups were carried out using the one-way ANOVA. If the result of the ANOVA test was significant, LSD test was used to identify which pairs of means were statistically different. Multiple linear regression was used for assessing the association between MetS components and Beck depression score. For all analyses, a two tailed $\mathrm{p}<0.05$ was considered statistically significant.

\section{Results}

A total of 157 participants attended in the present study. Demographic and clinical characteristics of the study population are shown in Table 1. Most subjects in all

Table 1. General characteristics, MetS parameters and Beck depression score of subjects based on study groups

\begin{tabular}{|c|c|c|c|c|}
\hline & $\begin{array}{l}\mathrm{MUO}^{1} \\
(\mathrm{n}=53)\end{array}$ & $\begin{array}{l}\mathrm{MHO}^{2} \\
(\mathrm{n}=64)\end{array}$ & $\begin{array}{l}\text { Non-obese metabolic healthy } \\
\text { group }(n=40)\end{array}$ & $\mathrm{p}^{*}$ \\
\hline & $\mathrm{SD} \pm$ mean & $\mathrm{SD} \pm$ mean & $\mathrm{SD} \pm$ mean & \\
\hline Age (year) & $37.98 \pm 5.84$ & $35.91 \pm 6.53$ & $35.91 \pm 6.26$ & 0.148 \\
\hline Weight (kg) & $91.47 \pm 13.34^{\mathrm{a}}$ & $89.09 \pm 12.76^{\mathrm{a}}$ & $70.45 \pm 6.95^{b}$ & $<0.001$ \\
\hline Height $(\mathrm{cm})$ & $171.48 \pm 7.56$ & $172.63 \pm 6.93$ & $172.65 \pm 6.23$ & 0.659 \\
\hline $\mathrm{WC}(\mathrm{cm})$ & $105.63 \pm 8.83^{\mathrm{a}}$ & $100.07 \pm 11.55^{\mathrm{b}}$ & $87.78 \pm 6.87^{\mathrm{c}}$ & $<0.001$ \\
\hline BMI $\left(\mathrm{kg} / \mathrm{m}^{2}\right)$ & $31.03 \pm 4.00^{\mathrm{a}}$ & $29.85 \pm 3.52^{\mathrm{a}}$ & $23.62 \pm 1.50^{\mathrm{b}}$ & $<0.001$ \\
\hline SBP & $125.21 \pm 12.39^{\mathrm{a}}$ & $116.31 \pm 11.41^{\mathrm{b}}$ & $114.13 \pm 10.50^{\mathrm{b}}$ & $<0.001$ \\
\hline DBP & $82.94 \pm 8.78^{\mathrm{a}}$ & $77.08 \pm 8.85^{\mathrm{b}}$ & $75.78 \pm 7.69^{b}$ & $<0.001$ \\
\hline FBS & $114.34 \pm 37.30^{\mathrm{a}}$ & $97.03 \pm 18.77^{\mathrm{b}}$ & $95.85 \pm 7.47^{\mathrm{b}}$ & $<0.001$ \\
\hline TG & $270.92 \pm 202.38^{\mathrm{a}}$ & $126.18 \pm 80.75^{\mathrm{b}}$ & $122.60 \pm 73.87^{\mathrm{b}}$ & $<0.001$ \\
\hline HDL & $50.90 \pm 8.27^{\mathrm{a}}$ & $54.89 \pm 6.25^{\mathrm{b}}$ & $55.47 \pm 9.25^{\mathrm{b}}$ & 0.007 \\
\hline Number of MetS components & $3.39 \pm 0.56^{\mathrm{a}}$ & $1.06 \pm 0.79^{\mathrm{b}}$ & $0.87 \pm 0.60^{\mathrm{b}}$ & $<0.001$ \\
\hline Beck depression score ${ }^{*}$ & $13.62 \pm 10.24^{\mathrm{a}}$ & $9.53 \pm 8.04^{b}$ & $9.10 \pm 9.28^{b}$ & 0.036 \\
\hline
\end{tabular}

1: Metabolically unhealthy obese, 2 : metabolically healthy obese

Values are analyzed by one-way ANOVA, values are mean \pm SD

Dissimilar values $(\mathrm{a}, \mathrm{b}, \mathrm{c})$ of each row are significantly different.

*Values are analyzed by ANCOVA; values are mean \pm SD, adjusted for sex, marital status and educational level. 
Table 2. Multiple linear regression for assessing the association between MetS components with Beck depression score

\begin{tabular}{|c|c|c|c|c|}
\hline \multirow[b]{2}{*}{ variables } & \multicolumn{2}{|c|}{ Model $1^{\mathrm{a}}$} & \multicolumn{2}{|c|}{ Model $2^{b}$} \\
\hline & $\bar{\beta}$ & $\mathrm{p}$ & $\beta$ & $\overline{\mathrm{p}}$ \\
\hline Age (year) & 0.117 & 0.327 & & \\
\hline Gender & 2.14 & 0,367 & & \\
\hline Marital status & 0.578 & 0.728 & & \\
\hline Educational status & 0.341 & 0.57 & & \\
\hline Weight (kg) & 0.080 & 0.118 & 0.088 & 0.091 \\
\hline Waist circumference $(\mathrm{cm})$ & 0.144 & 0.022 & 0.142 & 0.023 \\
\hline BMI $\left(\mathrm{kg} / \mathrm{m}^{2}\right)$ & 0.374 & 0.025 & 0.347 & 0.037 \\
\hline SBP & 0.010 & 0.866 & 0.027 & 0.655 \\
\hline DBP & 0.032 & 0.704 & 0.050 & 0.544 \\
\hline FBS & 0.095 & 0.001 & 0.096 & $<0.001$ \\
\hline TG & 0.003 & 0.540 & 0.002 & 0.722 \\
\hline HDL & -0.133 & 0.153 & -0.138 & 0.139 \\
\hline Number of MetS component & 1.87 & 0.001 & 1.71 & 0.002 \\
\hline
\end{tabular}

${ }^{\mathrm{b}}$ Adjusted for sex, age, marital status, and educational level.

groups were men. In terms of age, sex, and marital status, there were no statistically significant differences between the three groups.

After adjustment for sex, marital status, and educational level, MUO patients had a significantly higher Beck depression score than $\mathrm{MHO}$ and non-obese subjects $(\mathrm{p}=0.036)$ (Table 1$)$.

Linear regression analysis was used to assess the association between MetS components and depression score in all participants (Table 2). There was a significant association between WC $(p=0.022)$, BMI $(p=0.025)$, FBS $(p=0.001)$ and number of MetS components $(p=0.001)$. In a second model including adjustment for demographic variables (age, sex, marital status and educational level), there was a significant association between WC $(p=0.023)$, BMI $(p=0.037)$, FBS $(p<0.001)$, number of MetS components $(p=0.002)$ and depression.

\section{Discussion}

The present study aimed to compare the depression status, between metabolic unhealthy obese (MUO) subjects with age- and sex-matched healthy controls. Although a recent meta-analysis suggests that obesity is associated with an increased risk of depressive symptoms (2), literature are inconsistent $(4,15,16)$. One of the interesting findings of the current research was that the simultaneous presence of obesity and MetS in a person, compared with the presence of obesity without MetS, was associated with a higher depression score. The current study shows that MUO subjects had a higher Beck depression score than MHO and metabolically healthy non-obese subjects (Table 1).Accordingly, the obesity and depression seems to be dependent in the metabolic profile status. Evidence supporting this finding comes from several studies that report MUO to have higher odds of depression compared to $\mathrm{MHO}(6,9,11)$. However, to our knowledge, few studies have examined the risk of depression associated with MHO phenotype $(9,10)$. Several factors, especially metabolic factors need to be evaluated related to depression in obesity subtypes.

Another key finding of the current report is that FBS, $\mathrm{WC}$, and the number of MetS components were significant moderators of the relationship between the depression score and obesity subtypes. Elevated depression score in MUO increased almost linearly with increasing number of MetS components co-occurring with obesity. These findings remained consistent after adjusting for demographic variables including age, sex, educational level, and marital status. Previous analysis introduced WC and FBS as strong mediators of the association between depression and obesity phenotypes $(6,17)$. A more specific delineation of other moderators such as adipocytokine is warranted to understand the link between depression and obesity phenotypes better. In the current study TG, HDL-c and BP relationship with Beck depression (Table 2) was not significant. However, this finding was supported by a similar study conducted by Hamer et al. with a large sample size (3851 men and women) (6). Furthermore, as mention earlier in this manuscript, limited number of studies investigated the relation between metabolically unhealthy obese and depressive symptoms (6, 9-11), makes it difficult to discuss. However, according to previous studies, individual components of the metabolic syndrome including impaired glycaemic control and waist circumference appear to be particularly important in driving the association $(6,17)$, which was also observed in this study.

Several physiological mechanisms have been proposed as explanations for the increased risk of depression among MUO adults. For example, one of the driving factors might be disturbances in the hypothalamic-pituitaryadrenal axis, particularly in the regulation of cortisol, which is, in turn, contributes to glucose dysregulation, and insulin resistance and the cascade of events in the metabolic syndrome (18-20). Hypothalamic-pituitaryadrenal axis disturbances have been associated with the depressive symptom (21). Furthermore, in obese adolescents, depression may be explained by biochemical changes directly caused by disturbances in metabolic abnormalities, such as enlarged cerebrospinal fluid space and reduced white matter volume (22).

This study had some limitations. We did not assess metabolically unhealthy non-obese individual. In addition, the observational nature of these studies may not provide definite information to ascertain a cause and effect. Accordingly, further studies are needed to establish the 
relation between metabolic profile status and symptoms of depression.

\section{Conclusion}

We demonstrated that in obese subjects, metabolic profile status rather than obesity is associated with a higher risk of depression. The obesity and depression link seems to be dependent on metabolic profile status.

\section{Acknowledgments}

Our research group would like to thank all subjects who took part in the current study.

None of the authors has any competing interest. And no financial competing interest in relation to the work described (Ethic Number: 93-02-27-24976).

\section{Conflict of Interests}

The authors declare that they have no competing interests.

\section{References}

1. Atlantis E, Baker M. Obesity effects on depression: systematic review of epidemiological studies. Int J Obes.2008;32(6):881-91.

2. Luppino FS, de Wit LM, Bouvy PF, Stijnen T, Cuijpers P, Penninx BW, et al. Overweight, obesity, and depression: a systematic review and meta-analysis of longitudinal studies. Arch Gen Psychiatry. 2010;67(3):220-9.

3. de Wit L, Luppino F, van Straten A, Penninx B, Zitman F, Cuijpers P. Depression and obesity: a meta-analysis of community-based studies. Psychiatry Res. 2010;178(2):230-5.

4. Crisp AH, McGuiness B. Jolly fat: relation between obesity and psychoneurosis in general population. BMJ. 1976;1(6000):7-9.

5. Akbaraly TN, Kivimaki M, Brunner EJ, Chandola T, Marmot MG, Singh-Manoux A, et al. Association between metabolic syndrome and depressive symptoms in middle-aged adults: results from the Whitehall II study. Diabet Care. 2009;32(3):499-504.

6. Hamer M, Batty GD, Kivimaki M. Risk of future depression in people who are obese but metabolically healthy: the English longitudinal study of ageing. Mol Psychiatry. 2012;17(9):940-5.

7. Yosaee S, Khodadost M, Esteghamati A, Speakman JR, Shidfar F, Nazari MN, et al. Metabolic Syndrome Patients Have Lower Levels of Adropin When Compared With Healthy Overweight/Obese and Lean Subjects. Am J Men Health. 2017;11(2):426-34.

8. Stefan N, Kantartzis K, Machann J, Schick F, Thamer C, Rittig K, et al. Identification and characterization of metabolically benign obesity in humans. Arch Intern Med. 2008;168(15):1609-16.

9. Hinnouho GM, Singh-Manoux A, Gueguen A, Matta J, Lemogne C, Goldberg M, et al. Metabolically healthy obesity and depressive symptoms: 16-year follow-up of the Gazel cohort study. PloS one. 2017;12(4):e0174678.

10. Jokela M, Hamer M, Singh-Manoux A, Batty GD, Kivimaki M. Association of metabolically healthy obesity with depressive symptoms: pooled analysis of eight studies. Mol Psychiatr. 2014;19(8):910-4.

11. Phillips CM, Perry IJ. Depressive symptoms, anxiety and well-being among metabolic health obese subtypes. Psychoneuroendocrinology. 2015;62:47-53.

12. Executive Summary of The Third Report of The National Cholesterol Education Program (NCEP) Expert Panel on Detection, Evaluation, And Treatment of High Blood Cholesterol In Adults (Adult Treatment Panel III). JAMA. 2001;285(19):2486-97.

13. Szewczyk B, Kubera M, Nowak G. The role of zinc in neurodegenerative inflammatory pathways in depression. Prog Neuropsychopharmacol Biol Psychiatry. 2011;35(3):693-701.

14. Beck AT, Steer RA, Brown GK. Beck depression inventory-II. San Antonio. 1996;78(2):490-8.

15. Istvan J, Zavela K, Weidner G. Body weight and psychological distress in NHANES I. Int $J$ Obese Relate Metabol Dis. 1992;16(12):999-1003.
16. Magnusson PK, Rasmussen F, Lawlor DA, Tynelius P, Gunnell D. Association of body mass index with suicide mortality: a prospective cohort study of more than one million men. Am J Epidemiol. 2006;163(1):1-8.

17. Zaninotto P, Pierce M, Breeze E, de Oliveira C, Kumari M. BMI and waist circumference as predictors of well-being in older adults: findings from the English Longitudinal Study of Ageing. Obesity (Silver Spring, Md). 2010;18(10):1981-7.

18. Joseph JJ, Wang X, Spanakis E, Seeman T, Wand G, Needham B, et al. Diurnal salivary cortisol, glycemia and insulin resistance: The multi-ethnic study of atherosclerosis. Psychoneuroendocrinology. 2015;62:327-35.

19. Stetler C, Miller GE. Depression and hypothalamic-pituitary-adrenal activation: a quantitative summary of four decades of research. Psychosom Med. 2011;73(2):114-26.

20. Licht CM, Vreeburg SA, van Reedt Dortland AK, Giltay EJ, Hoogendijk WJ, DeRijk RH, et al. Increased sympathetic and decreased parasympathetic activity rather than changes in hypothalamic-pituitary-adrenal axis activity is associated with metabolic abnormalities. J Clin Endocrinol Metab. 2010;95(5):245866.

21. Koenigsberg HW, Teicher MH, Mitropoulou V, Navalta C, New AS, Trestman R, et al. 24-h Monitoring of plasma norepinephrine, MHPG, cortisol, growth hormone and prolactin in depression. J Psychiatr Res. 2004;38(5):503-11.

22. Yau PL, Javier DC, Ryan CM, Tsui WH, Ardekani BA, Ten S, et al. Preliminary evidence for brain complications in obese adolescents with type 2 diabetes mellitus. Diabetologia. 2010;53(11):2298-306. 